\title{
EL PROJECTE INTEL·LECTUAL DE BALTASAR PORCEL EN EL TARDOFRANQUISME (1965-1972)
}

\author{
FRANCESC FOGUET I BOREU
}

\begin{abstract}
Baltasar Porcel was classified by the Liaison Office of Franco's government as a writer of "separatist" ideas. This paper details the content of the 1965-1972 Porcel dossier, kept by the repressive Francoist regime, and compares it with a detailed analysis of his non-fiction works during that period. The main purpose of this paper is to present the intellectual project designed by Porcel in a context of new awareness of the situation and a general debate regarding Catalonia's position and role in Spain. Porcel's published books (travel, interviews, literary articles, columns, essays) can be used to identify more precisely his ideological affiliation during the late Francoist era. Porcel was clearly not a "separatist". As a writer and polemicist during that period, Porcel wrote from a sui generis leftist Catalanist perspective, seeking to shape Catalan and Spanish public opinion for two reasons: to systematically demystify bourgeois Catalanism from a more progressive perspective; and to build bridges of dialogue with intellectuals in the rest of Spain and improve how Catalonia is known and understood beyond its borders.
\end{abstract}

"Era llavors del Maig del 68, la contracultura, la fi del règim franquista i tota la pesca. Era una època. En la qual jo ja era també i de molt abans catalanista." (Baltasar Porcel, Ulisses a alta mar 85)

A les acaballes de la dècada de 1960, Baltasar Porcel havia aconseguit ser una de les veus més irreverents i polèmiques del moment, sobretot a través del periodisme. Escrivia tant a les capçaleres de Barcelona com de Madrid i, a més de la literatura de ficció, havia publicat cròniques de viatges, assaigs i reculls d'entrevistes d'un notable ressò. El contrast entre l'encasellament que en féu l'Oficina de Enlace un organisme creat el 1962 per la dictadura franquista amb la comesa de controlar les activitats subversives - i la ideologia que destillava la seva obra de no ficció resulta ben simptomàtic de les referències, escasses i superficials, que tenia l'aparell repressiu franquista sobre la filiació ideològica de Porcel entre 1965 i 1972, si més no, dates extremes de la documentació conservada. 
L'expedient de Baltasar Porcel a l'Oficina de Enlace - dipositat a l'Archivo General de la Administración d'Alcalá de Henares (caixa 42/08849, sobre 24) - conté únicament, com a documentació substantiva, una fitxa policial sobre l'escriptor mallorquí de 1965 i dos informes, datats a Madrid, el 23 de maig de 1967 i el 13 de febrer de 1970, respectivament (cf. l'Annex 1-3). Si en la fitxa s'especificava que Porcel no tenia antecedents en els arxius policials i que se'n desconeixia la ideologia, en els dos informes posteriors se'l classificava, ras i curt, com a "separatista". El motiu del primer era la publicació d'un fragment de la seva peça teatral "Història d'una guerra" al Diario de Mallorca, el 26 d'abril de 1967. Les dades personals i familiars de Porcel que hi figuraven eren secundades per la informació oral recollida en testimonis andritxols (potser pel destacament local de la Guàrdia Civil) que el tenien en molt poca consideració ("por haber escrito, en libros y periódicos, sátiras contra ellos”), que recelaven que visqués amistançat amb l'escriptora Concha Alós i que, per a més inri, tingués uns ideals polítics d'esquerres i combregués amb "las ideas separatistas de los catalanes". Així mateix, s'hi consignava el ventall de familiars de Porcel de filiació dretana i afectats al règim, s'hi anotava la vinculació que mantingué amb Camilo José Cela, del qual fou de jove ajudant, i s'hi relacionava la llista de publicacions en què colllaborava (Diario de Barcelona, La Vanguardia Española, Destino, Serra d'Or) i de llibres que havia publicat "al estilo de Sartre y Camus" (Els condemnats, Solnegre, Els escorpins). Com que l'informe no era degut a cap denúncia, cal deduir que la seva inclusió en l'expedient es feia ben bé d'ofici.

No deixa de ser sorprenent, tanmateix, que l'origen d'aquest primer informe fos un fragment d' "Història d'una guerra", una obra del mateix Porcel que fou publicada, sense problemes de censura, dos anys abans dins del volum Teatre (1965). En tot cas, als responsables de la "Sección Bis del Estado Mayor Central del Ejército" que signaven el document no els passà per alt — potser perquè els recordava una situació similar - la doble crítica que es feia en el text de ficció objecte de litigi: d'una banda, de la displicència dels dirigents polítics i dels comandaments militars envers els milers de soldats morts al front, unes baixes que no afectaven els oficials que sabien com sortir-se'n, i, de l'altra, de la satisfacció dels sectors financers perquè trobaven en la guerra una bona oportunitat per fer negoci. Una guerra, de més a més, que havia estat providencial per resoldre el "marasme perillós" en què havia caigut el règim polític establert.

El segon informe recollia bona part de les dades del primer, però en matisava alguns aspectes i n'afegia altres. La seva filiació ideològica continuava essent la mateixa, per bé que expressada en una fórmula que prescindia de l'eix social i es limitava al nacional: "Se le considera como persona cuyas ideas políticas se 
inclinan hacia el separatismo catalán". A més de destacar la seva colllaboració a La Vanguardia Española, Destino i Serra d'Or, hi certificava que era escriptor "tanto en castellano como en catalán” i que havia obtingut el premi Ramón Godó de La Vanguardia el 1968. Altres dades interessants que s'hi inventariaven eren la denegació, el maig de 1969, del passaport per viatjar a Rússia, com a acompanyant de José Manuel Lara, l'editor de Planeta; la signatura del manifest adreçat, el desembre de 1968, al ministre de Governació, "denunciando supuestos malos tratos a presos y detenidos políticos", i la seva participació com a conferenciant en el Club d'Amics de la UNESCO.

A banda d'aquests tres documents substanciosos, el dossier porcelià a l'Oficina de Enlace només consta d'una fotocòpia de l'entrevista "A tumba abierta. Encuentro con Baltasar Porcel" que li féu Juan Carlos Clemente al Diario de Barcelona i que es publicà el 30 de gener de 1972. Una mà anònima s'encarregà de remarcar-ne diversos fragments ben significatius del pensament i de la praxi de Porcel com a escriptor (cf. l'Annex 4). Segons que hi declarava, el mòbil que el dugué a dedicar-se al periodisme fou la desconfiança en la versió oficial dels fets i la necessitat d'indagar en la vida real del país. Entre les entrevistes que havia emprès, reconeixia la impressió satisfactòria que li causà Dionisio Ridruejo - un dels franquistes renegats que li semblà "moralmente muy digno" - mentre que malparlà en bloc de la classe política que considerava "bastante inmoral o al menos amoral". Entre els fragments subratllats, també hi ha la reflexió que feia sobre el bon nivell de la cultura catalana, tot i els condicionaments estructurals, i les disquisicions sobre l'ús del català (en l'obra de creació) i del castellà (en el periodisme), una dualitat que atribuïa a les circumstàncies històriques heretades i al caràcter minoritari de la cultura catalana, a la qual s'adscrivia sense ambigüitats.

Ben mirat, és desconcertant que no hi hagi cap al·lusió, en l'expedient porcelià a l'Oficina de Enlace, a les activitats clandestines en què participà el jove aprenent d'escriptor, durant els primers mesos del seu aterratge a Barcelona, com a membre d'una cèlllula catalanista capitanejada per Joan Triadú, que rebia ordres directes de Jordi Pujol (Planas 58-62). Ni tampoc s'hi consigna la signatura d'altres escrits de protesta, apareguts en un context de conflictivitat social creixent, com ara l'adhesió dels intel-lectuals catalans a la carta de 1962 de Ramón Menéndez Pidal "invitando a ejercer el derecho de petición" (Juliá 441), la missiva de 1965 de suport a l'abat de Montserrat Aureli Maria Escarré o l'adhesió solidària a l'homenatge al poeta Celso Emilio Ferreiro de 1966. No obstant això, tot fa pensar que n'era més aviat poc entusiasta, perquè el seu nom no figura en altres manifestos antifranquistes importants signats per personalitats de les lletres i de la cultura amb qui mantingué una molt bona relació. 
Tot i que d'una manera més subtil, dos dels seus primers llibres de viatges d'inspiració illenca, Arran de mar. Viatges i fantasies (1967) i Viaje a las Baleares menores (1968) aporten pinzellades crítiques sobre la realitat coetània del país i una comuna voluntat desmitificadora. Amb la intenció de trencar tòpics inveterats, com féu també a Els xuetes (1969), el primer aplega escrits literaris diversos dedicats al paisatge i a la gent de mar, en què, de biaix o directament, s'hi esmenten els estralls causats per l'eufòria del turisme, els problemes de la immigració o la irrupció del món modern que havien capgirat la fesomia de les Illes. Porcel hi retrata també alguns tipus mallorquins discrepants de l'Espanya oficial i dels seus mites endèmics que remeten al temps de la República (l'oncle Nofre) o posen en dubte la hispanitat (Joanot Colom). Sense complexos, hi evocava en positiu, a més, algun personatge menystingut per la història oficial, com ara l'escriptora George Sand. Recull d'articles publicats originalment a La Vanguardia Española, el segon verificava - a grans trets - el creixement del turisme i l'amenaça del cosmopolitisme i del capitalisme desaforats com a elements trasbalsadors del paisatge i la vida illencs.

A Las sombras chinescas (1968), Porcel no tan sols recuperava alguns dels tipus o personalitats d'Arran de mar (Nofre, Colom, Sand), sinó que també n'introduïa algun altre (l'oncle Montserrate), que invocava la duríssima repressió a Mallorca el 1936, o el culte i educat rei José Bonaparte, contrafigura de la mitologia oficial. Amb una desinhibició similar, comentava determinats episodis de la història de Catalunya: els atemptats anarquistes de Santiago Salvador al Liceu el 1893, l'aixecament llibertari a Fígols el 1932 o els afusellaments de republicans que els feixistes perpetraren l'estiu de 1936 a Mallorca. De manera més tangencial, així mateix, treia ferro al mite del comte Arnau, denunciador en el fons dels abusos dels poderosos, i a la transcendència del Pi de les Tres Branques, com a símbol del catalanisme.

Amb una mirada igualment irreverent, pragmàtica i un punt melangiosa que en alguns passatges recorda Pla - Porcel convocava a Las sombras chinescas, com ja havia fet en català a Arran de mar, paisatges i gent de les Illes i altres indrets que esquerdaven el cofoisme i la monotonia de la propaganda franquista. "Resulta interesante rascar en el país, levantar las verdades oficiales", hi escriu inadvertidament (Porcel, Las sombras 228). Un dels aspectes més rellevants dels dos volums suara esmentats és la visió crítica del turisme com una font de riquesa extraordinària per a la costa de les terres catalanes, sobretot perquè resultava excessiu i desnaturalitzador: conduïa a perpetrar barbaritats urbanístiques, especular amb els diners i viure una "festa permanent". Era un turisme desbridat que, per la inoperància i la desatenció estatals, no tenia les infraestructures viàries ni els serveis adequats per desenvolupar-se com calia. 
A diferència dels articles més divagatius de Las sombras chinescas, a Exercicis més o menys espirituals (1969), l'escriptor mallorquí hi antologava escrits sobre la problemàtica cívica i cultural del país amb la intenció de "contribuir a airejar i normalitzar la realitat collectiva dels Països Catalans, des de dintre i des de la circumstància actual" (Porcel, Exercicis 5). Explícitament, amb unes peces bona part de les quals havien estat publicades a Telelestel i a La Vanguardia Española, es proposava de confegir un "testimoni actiu i punyent d'un país en un temps" (Porcel, Exercicis 7). La seva voluntat d'incidència partia d'una declarada desmitificació de les nostàlgies del passat i d'una recerca de les realitats dinàmiques que trobava a Barcelona, València i Palma. Des del seu punt de vista, la clau de volta era la capacitat de Barcelona - com a centre polític, socioeconòmic i cultural - d'exercir de motor "d'irradicació i de recuperació de la cultura catalana" (Porcel, Exercicis 26). Davant dels perills de la mundialització, la societat catalana havia d'enriquir-se i esbatanar portes i finestres a Europa, sense deixar d'aprofundir en la seva catalanització.

Les cavillacions porcelianes no s'estaven d'apuntar la gran influència de la dreta indígena en la cultura catalana amb les seves llums i ombres, tot reivindicant la figura de Prat de la Riba com un model actualitzable. Des d'una perspectiva històrica sui generis, però sempre atenta al present i al futur, Porcel denunciava el desconeixement que a Madrid es tenia de la realitat catalana i la tendència de la capital espanyola a l'absorció més que no pas a la integració, una rèmora que feia difícil l'intervencionisme polític i cultural capitanejat per la "nova burgesia catalana" - un concepte manllevat d'Ernest Lluch. Un perill semblant de dilució cultural l'oferia el cosmopolitisme. Per bé que fos favorable al progrés i a l'obertura cap a enfora, Porcel (Exercicis 65) es preguntava quin sentit tenia l'enriquiment desaforat que generava el negoci turístic - creixent a les Illes - si conduïa a difuminar la cultura i la societat catalanes "darrere el descoloriment cosmopolita". Defensor d'una riquesa material i d'una democràcia política que garantissin tant el progrés industrial com el cultural, es planyia que el turisme no hagués generat, a Mallorca, una nova classe - com en part féu la burgesia principatina a final del XIX - capaç de "construir unes plataformes ideològiques i culturals que fossin, alhora, les seves columnes i els seus servidors" (Porcel, Exercicis 72).

La cultura, autèntic cavall de batalla per a Porcel, era l'eix central de la segona part d'Exercicis més o menys espirituals. Encara que focalitzades en la divulgació de temes mallorquins, les indagacions porcelianes tendien a qüestionar llocs comuns, com el concepte de "Decadència" (segles XVI-XVIII), que creia restrictiu, car menysvalorava la realitat cultural més popular, o la visió reduïda del modernisme, que no era tan sols un corrent artístic, sinó un moviment 
sociocultural. A més, Porcel subratllava i reivindicava aspectes desconeguts o mal coneguts, com la importància dels narradors insulars, el pensament conservador mallorquí o la figura intel-lectual de Gabriel Alomar. L'objectiu de fons era superar l'etapa de subsistència i fer el salt cap a la normalitat cultural, a despit de les dificultats pel fet de ser una cultura petita, amb una tradició intermitent i sense suports d'institucions pròpies.

Des d'una òptica pragmàtica, l'escriptor mallorquí es proposava de fer un "examen de país" com més ampli millor, que abracés tots els àmbits possibles (història, economia, sociologia, política) i que valorés totes les manifestacions culturals en llengua catalana (el cinema, la literatura, el teatre o la cançó). No es tractava de resignar-se a una "cultura iceberg", sinó que calia que, sense renunciar a l'especificitat, fos oberta i universal, "exposada al sol" (Porcel, Exercicis 126). Un dels vessants d'aquesta cultura, la literatura, era objecte d'especial atenció en la tercera part d'Exercicis més o menys espirituals, en la qual recollia una tria de retrats subtils i sovint atrevits d'alguns dels escriptors que admirava: Víctor Català, Eugeni d'Ors, Josep Pla o Joan Fuster. La predilecció per aquests dos darrers resulta palmària. Amb motiu de l'edició de les seves Obres Completes, Porcel trencava una llança a favor de Pla, situant-lo al mateix nivell dels elogiats Riba i Espriu, i no dubtava a qualificar-lo com el primer escriptor català contemporani. La figura de Fuster, "el primer assagista del país", era valorada també de manera encomiàstica: "l'arribada literària de Joan Fuster va abastar proporcions de vitalitat escriptural de gran volada, que van oscilllar entre l'assaig lliure o la crítica literària brillant d'un costat i de l'altre la cabriola intel-lectual d'una irreverència i d'una manca de prejudicis magnífiques" (Porcel, Exercicis 173-74). En bona part, l'obra periodística de Porcel compartia afinitats, en la intenció i els objectius, no tant en la ideologia, amb la de Pla i Fuster.

D’un abast més internacional, els seus assaigs El conflicto árabe-israelí (1969) i Desintegraciones capitalistas (1972) eren el fruit de les experiències de viatge i de l'estudi aprofundit dels temes tractats. El primer es proposava d'analitzar l'enfrontament entre Egipte i Israel des d'una posició neutra i amb la convicció que només la pau i la comprensió mútua podien resoldre el conflicte. Tot i aquesta pretesa equidistància, Porcel criticava la tendència del món musulmà a fer castells en l'aire sense tenir en compte la realitat i, en canvi, mostrava una evident fascinació per l'eficàcia política d'Israel. Davant de les aspiracions genocides dels àrabs i els seus deliris militaristes, hi oposava la colonització hebrea de noves franges de terra que incorporava al seu territori, tot apel-lant a la supervivència 
i al dret d'autodefensa. En contrast amb una caòtica situació política i social al món musulmà, els jueus podien fer efectiva la seva "enorme voluntad nacionalista y creadora" (Porcel, El conflicto 54), una idea que veia aplicable també a altres països. Enfront d'un Islam subdesenvolupat, predominantment agrícola, Israel podia exhibir el domini de la tècnica i de la ciència.

En les seves anàlisis de la situació del conflicte, alternades amb les descripcions del viatge a la zona, Porcel repartia retrets tant per als àrabs com per als israelians, tots dos atrinxerats en la política de la força, però no podia evitar de decantar-se pels jueus o, si més no, de justificar-ne les actuacions en el vesper de l'Orient Mitjà. Partidari d'una solució pacífica, creia que el desllorigador era la creació d'un Estat palestí. Algunes de les observacions de Porcel podien tenir, d'altra banda, una doble lectura en clau interna, com ara el suggeriment implícit del model de progrés que oferia l'Estat d'Israel per al nacionalisme català o la crítica a la petulant grandiloqüència de les dictadures, fossin reaccionàries o progressistes, en al·lusió al cas espanyol.

Al seu torn, Desintegraciones capitalistas diagnosticava, amb vagues aires anarquitzants a l'estil de La revuelta permanente (escrita el 1970 i publicada el 1978), l'extinció d'unes formes de vida i uns models culturals del capitalisme, tot partint de tres grans nuclis simbòlics: Nova York, ciutat emblemàtica de la primera potència mundial; París, capital de la revolta europea, i Eivissa i Formentera, refugi de la utopia d'alliberació hippy. Molt crític amb el capitalisme, que definia com "la ley de la selva, la destrucción y sujeción de los de abajo por los de arriba" (Porcel, Desintegraciones 30 ), les seves reflexions exposaven la corrupció política, social i moral de la societat americana i europea. Amb una clara voluntat desmitificadora, similar a la que havia emprat per radiografiar Catalunya, Porcel n'illuminava els llocs comuns i les parts més fosques. Dels Estats Units d'Amèrica, en subratllava els índexs de pobresa, marginació i criminalitat, els conflictes entre comunitats, els moviments feministes. Tot comentant el cas francès, trasbalsat pel Maig del 68, desaprovava l'actitud mimètica i acrítica de la intel-lectualitat catalana i espanyola d'esquerres, massa pendent del model filocomunista francès que, contrari a l'estalinisme i a l'URSS, elogiava paradoxalment "Trotsky, el leninismo puro y Tito" (Porcel, Desintegraciones 94). Com a reacció a la societat de consum i a la guerra del Vietnam, el moviment hippy era interpretat com una fugida de caràcter individual, plena de contradiccions, el revers de la qual podia ser "la dependencia del giro mensual de la familia, el nomadismo infructuoso, la idiotización por la droga" (Porcel, Desintegraciones 119).

Com indicava al final del volum, les experiències del viatge que hi relatava van servir per constatar críticament, sobre el terreny, la realitat, en una orientació semblant als seus llibres Cataluña vista desde fuera (1970), Los catalanes hoy (1971) o Los encuentros (1969; 1971). Entre altres afirmacions polèmiques que conté 
l'assaig i que podien llegir-se en clau espanyola, Porcel expressava el menyspreu cap als polítics, que considerava capaços de qualsevol cosa per conservar el poder, i especialment els d'edat avançada que s'hi aferraven desesperadament (en una velada referència al dictador Franco), i, com en El conflicto árabe-israelí, criticava la perversió de les dictadures - capitalistes o comunistes - i mostrava el desacord tant amb el reaccionarisme tout court com amb el neocapitalisme a l'americana.

La voluntat globalitzadora que apuntava a Exercicis més o menys espirituals tingué un complement lògic en els volums recopilatoris d'entrevistes que veieren la llum a final de la dècada dels seixanta i primeríssims dels setanta: Los encuentros (1969-1971), Los catalanes de hoy (1971) i Grans catalans d'ara (1972). Publicat originàriament a Destino, el centenar d'entrevistes de Los encuentros - un títol inspirat en Gli incontri, d'Indro Montanelli, i influït per Pla i Azorín arrencava del neguit porcelià per conèixer la realitat sense les mediacions oficials ni institucionals. Com advertia en la nota prèvia, els seus intervius no defugien la crítica ni la polèmica $i$, dins dels marges que permetia la censura, se situaven "a contrapelo del triunfalismo imperante", atès que la seva pretensió no era de "bañarse en agua de rosas, sino la de ir configurando una imagen del país a través de los problemas, los hombres y las realizaciones más características" (Porcel, Los encuentros I 8).

Los encuentros dedicava un espai considerable a personalitats del món cultural, polític, econòmic i intellectual espanyol, des de les ben situades en l'establishment fins a les que despuntaven en l'oposició antifranquista, tot passant per les que s'ubicaven en estadis intermedis més o menys "possibilistes" o "evolucionistes", les unes i les altres preocupades per albirar vies de sortida al règim i adaptar-se a les transformacions polítiques del moment. Al marge de la irreverència o la impertinència amb què abordava de vegades els seus retrats, Porcel no deixava de manifestar una indissimulada fascinació per alguns dels factòtums del poder econòmic i social del tardofranquisme.

Alternant amb les entrevistes a les personalitats espanyoles (Vicente Aleixandre, José María de Areilza, Antonio Buero Ballejo, Miguel Delibes, José Luis López Aranguren, Dionisio Ridruejo, Alfonso Sastre, Ramón Serrano Suñer, per citar-ne algunes), els dos volums de Los encuentros abracen un ventall representatiu de figures destacades en diversos àmbits de la cultura i la intel-lectualitat catalanes: les lletres (Josep Pla, Joan Teixidor, Joaquim Molas, Josep Maria Castellet, Manuel de Pedrolo, Néstor Luján, Gabriel Ferrater, Llorenç Villalonga, Blai Bonet, Joan Fuster, Salvador Espriu, Joan Oliver, Mercè Rodoreda), l'escena (Joan Capri, Núria 
Espert), l'arquitectura (Oriol Bohigas, Antoni de Moragas), la filosofia (Josep Ferrater Mora), la religió (Josep Dalmau, Jordi Llimona), la filologia (Francesc de Borja Moll, Ramon Aramon), la història (Ramon d'Abadal, Ferran Soldevila), les arts (Josep Maria Subirachs, Antoni Tàpies, Andreu Alfaro, Modest Cuixart, Apel·les Fenosa) o la cançó (Raimon, Joan Manuel Serrat), entre molts d'altres.

A banda de les visions crítiques sobre la realitat coetània que segregaven alguns dels retratats, un dels temes recurrents de Los encuentros és l'encaix del fet diferencial català en l'Espanya del futur, un cop superada la dictadura de Francisco Franco. Grosso modo, les posicions dels entrevistats espanyols anaven des del paternalisme tardofranquista dels integrats, que apel-laven al respecte de les aspiracions catalanes o al tracte paritari de la llengua i la cultura perifèriques, a la denúncia de l'hegemonia castellana i del centralisme madrileny que feien alguns dels membres de l'oposició al règim - Aleixandre o Delibes, per exemple - defensors de la varietat dins de la unitat. Atenent a allò que es podia dir i a allò que només es podia insinuar, els intervius també deixen entreveure les expectatives coetànies de canvi de la societat catalana i espanyola cap a un sistema democràtic, envers les quals calia que els professionals de la cultura i de les arts estiguessin - com apunten algunes veus - a l'altura de les circumstàncies. A partir del vell símbol europeu dels Cavallers de la Taula Rodona, Porcel (Los encuentros I 241) es mostrava partidari que els intel-lectuals catalans i espanyols s'asseguessin a conversar tranquil·lament en una taula rodona - en peu d'igualtat, doncs - per poder conèixer de primera mà les realitats variades de l'Espanya del moment.

Una atenció especial mereix l'opinió sobre el fet diferencial català de tres dels protagonistes, el 1970, de la taula rodona "Catalunya vista des de Castella", publicada al número 125 de Serra d'Or (1970), el contingut de la qual motivà l'obertura a Porcel d'un expedient pel temut Tribunal de Orden Público (TOP): José Luis Aranguren, Pedro Laín Entralgo i Joaquín Ruiz-Giménez. Aranguren - expulsat de la universitat oficial — declarà obertament a l'escriptor mallorquí que, a l'Espanya franquista, es trobava limitat per totes bandes, encara que tenia un marge d'actuació per treballar en els seus llibres, rebre visites, impartir cursos i àdhuc assistir a trobades entre la intel-lectualitat castellana i la catalana. Respecte al "problema catalán", Aranguren era partidari de la necessària coexistència, imprescindible per a l'estabilitat política, mentre que Laín - ben situat en les estructures científiques del règim - apostava per resoldre "la inserción de la Cataluña real en la vida total de España" (Porcel, Los encuentros I 72) i Ruiz-Giménez - exministre d'Educació i Ciència i fundador de Cuadernos para el Diálogo - esgrimia l'exigència de comprensió i diàleg i, alhora, defensava la pluralitat com a antídot al centralisme. Altres parers remarcables sobre aquest punt eren el del díscol Dionisio Ridruejo - potencial membre de la taula rodona - que considerava que l'Estat espanyol havia d'adoptar "la forma asociativa o federal si 
queremos que todos lo tengan igualmente por suyo" (Porcel, Los encuentros I 132), i el del professor Enrique Tierno Galván que definia Espanya com a "comunidad de comunidades" (Porcel, Los encuentros II 240).

Grans catalans d'ara (1972) partia de les entrevistes retrat publicades abans a Serra d'Or, excepte la de l'abat Escarré, que fins aleshores era inèdita, i se centrava en un ampli ventall de personalitats catalanes de dimensió internacional del segle xx. Com en el cas de Los encuentros, el propòsit era aprehendre "una imatge d'un país" de manera directa, no mediatitzada per la visió institucional o propagandística, ni tampoc per mitificacions interessades: "fent-ho, com és notori, d'una manera europea, sense trèmuls almogàvers, sense inflar el gos, sinó amb asprivor, amb ironia, amb coneixement i reconeixement" (Porcel, Grans 7-8). Els trenta intervius del volum eren classificats en cinc apartats que aliaven "idees, generació i obra" (Porcel, Grans 10) dels entrevistats, pertanyents a àmbits molt diversos de la cultura, les arts, les lletres, les ciències o la intellectualitat catalanes: "El país ideal” (Víctor Català, Josep Carner, Pau Casals, Jordi Rubió, Ramon d'Abadal i Pere Bosch Gimpera), "Entre l'ideal i el conflicte” (Joan Miró, Josep Pla, Ferran Soldevila, Josep Trueta, Rafael Benet, Josep Lluís Sert), "Del naufragi a la represa" (Joan Oliver, Francesc de Borja Moll, Llorenç Villalonga, Joan Sardà, Mercè Rodoreda i Miquel Batllori), "Dins la reconstrucció" (Salvador Espriu, Aureli Maria Escarré, Josep Ferrater Mora, Joan Triadú, Antoni Maria Badia i Margarit i Manuel de Pedrolo) i "Camins cap a demà" (Joan Fuster, Antoni Tàpies, Joaquim Molas, Raimon, Josep Maria Castellet i Gabriel Ferrater). Entre les figures que hi eren clarament més ben valorades, excel·lia altre cop la de Josep Pla, l'obra del qual era considerada com "una de les dues o tres més importants que ha donat Catalunya en aquest últim quart de segle. O potser la més important" (Porcel, Grans 126).

Amb un estil més directe i incisiu que a Los encuentros, però igualment indiscret $\mathrm{i}$ irònic, les peces de Grans catalans d'ara acomplien l'objectiu desmitificador a què aspirava Porcel, sobretot en la secció "El país ideal". Una de les constants que bategava en el seu discurs d'entrevistador - a voltes insolent - era la de deixar-se de nostàlgies i partir d'evidències, de realitats, bo i albirant més cap al demà que no pas enyorant el passat. A l'entradeta de l'interviu dedicat a Pere Bosch Gimpera, el mateix Porcel es vanagloriava de ser el qui més havia fet per donar a conèixer, més enllà de la "propaganda catalanesca" i del cofoisme que se'n derivava, "personatges mitificats per haver emprès els camins de l'exili i per restar en la subterraneïtat interior, després de la guerra civil" (Porcel, Grans 91). En altres 
peces, l'entrevistador hi feia acotacions que són d'un gran interès. Per exemple, en la de Josep Trueta, comentava irònicament, de passada, el seu assaig The Spirit of Catalonia (1946), del qual retreia que el dibuix que confeccionava de l'esperit català denotava "una fuga romàntica i idealista" (Porcel, Grans 165). En la de Josep Lluís Sert, el bon moment de l'arquitectura en la preguerra el duia a inferir que la desfeta de 1939 havia suposat una reculada en l'evolució progressiva del país: "una època prehistòrica, sense institucions, sense paper imprès, sense mestres, entre les ombres de les cavernes" (Porcel, Grans 187). En l'interviu a l'economista Joan Sardà, Porcel li preguntava si creia que "sense una obertura política" es podia "encarrilar i solucionar la problemàtica econòmica espanyola", una qüestió que l'entrevistat mirava de respondre amb vaguetats que no fossin gaire comprometedores (Porcel, Grans 242). En les paraules preliminars a la peça consagrada a Antoni Maria Badia i Margarit, Porcel (Grans 341) hi feia una reflexió, inusualment solemne, d'abast sociolingüístic: "la llengua, essent com és el fet diferencial català més evident, ha substituït al país la manca d'institucions autòctones. La importància de l'assumpte és radical. Lluitar per la llengua, agitar-la com una bandera, ha estat i és una necessitat consubstancial al nostre ésser”. Una declaració que contrastava, tanmateix, amb la rèplica intencionada a la tesi pedroliana - en virtut de la qual calia delimitar la literatura catalana a la que s'expressava en català - que semblava una autojustificació personal, atès que es planyia que l'escriptor indígena se sentís "moralment obligat per una opinió maximalista a rebutjar l'ús instrumental de la segona llengua, la castellana" (Porcel, Grans 371), fet que li impedia l'accés als mitjans de comunicació i, per tant, el privava de la possibilitat de professionalitzar-se, projectar l'opinió als lectors catalans i reivindicar Catalunya a Espanya, on era ignorada. Finalment, en el preludi a l'entrevista a Raimon, Porcel (Grans 421) s'hi queixava irònicament que s'acusés al cantant de Xàtiva de "fer política", per tal com, en realitat, tot allò que afectava els homes ho era.

Des del punt de vista ideològic, les entrevistes retrat més remarcables són les que va fer a Ramon d'Abadal, Aureli Maria Escarré, Joaquim Molas i Josep Maria Castellet. Membre del consell privat de Joan de Borbó, Abadal hi defensava la solució monàrquica $\mathrm{i}$, davant la insistència de Porcel, rebutjava enèrgicament la instauració de la república perquè, en la seva opinió, "la passada fou un desgavell i ens portà la Guerra Civil. I si en venia una altra, aniria seguida d'una dictadura militar al cap de poc temps" (Porcel, Grans 85). Exiliat - com és sabut - per raons polítiques, Escarré reconeixia l'enfrontament obert amb el govern franquista, reclamava la democratització i la humanització de l'Església, i confiava que l'Estat espanyol aconseguiria, amb democràcia i llibertat, situar-se al nivell dels altres pobles europeus. En al-lusió a la manca de llibertats, Molas reclamava "uns canvis profunds d'estructura" (Porcel, Grans 418) que fessin possible millorar el panorama cultural coetani, considerat insatisfactori per les dificultats d'articular 
una vida universitària activa, uns mitjans d'informació sòlids i lliures, un sistema literari ampli i solvent. Com en el cas de Molas, Porcel aplaudia, finalment, la diagnosi de Castellet sobre la gran confusió que observava a Catalunya per raons lingüístiques i polítiques, i sobre la necessitat de desmitificar, aclarir posicions o, pel cap baix, denunciar el desgavell regnant.

Molt més circumstancial, adreçat al públic lector espanyol, Los catalanes de hoy (1971) aplegava una triadella de les entrevistes ja publicades a Grans catalans d'ara. Les divuit personalitats escollides representaven "una cota alta y a veces excepcional de la cultura que se viene realizando no sólo en los Países Catalanes, sino en el ámbito de lo que venimos llamando cultura en el mundo de nuestro tiempo" (Porcel, Los catalanes 9). Una mostra que oferia una parcellla viva dels diversos àmbits de la cultura catalana per incitar el lector espanyol a aprofundir en el seu coneixement. Hi eren representades figures insignes del món de les lletres (Català, Espriu, Carner, Pla, Rodoreda, Villalonga, Oliver, Fuster), de la història i la crítica literàries (Rubió, Molas, Castellet), de les arts (Miró, Tàpies), de la música (Casals, Raimon), de la història (Abadal), de la filosofia (Ferrater Mora) i de la medicina (Trueta). Com prevenia la nota liminar inicial, la selecció oferia una visió més aviat pessimista del panorama general que era atribuïble al fet que la catalanitat esdevenia "un ideal y una realidad no realizados" (Porcel, Los catalanes 10).

En parallel a Los encuentros i Grans catalans d'ara, en què explorava els topants del país i les relacions entre Madrid i Barcelona, Porcel publicà Cataluña vista desde fuera (1970), un volum que, com indicava en el preàmbul, tenia una motivació periodística $\mathrm{i}$ estava sotmès temàticament a "las dificultades de orden político" (Porcel, Cataluña 10). Malgrat aquestes limitacions, creia que era necessari per trencar el gel i començar a parlar obertament de "la laberíntica cuestión de Cataluña vista desde Castilla" (Porcel, Cataluña 10). L'eix del llibre era la transcripció original de la taula rodona que havia estat publicada a Serra d'Or i expedientada pel TOP (amb només un parell de canvis menors, però significatius, en les respostes a la pregunta final: el "problema del nacionalisme català" passava a ser el "problema catalán", i els "pluralismes nacionals", els "pluralismos" a seques). Acompanyant aquest text, que es rebatejà amb el títol "Cataluña y su problemática vista desde Madrid”, Porcel hi reproduí també les entrevistes als catalanistes Pierre Vilar i Giuseppe Sansone (aparegudes abans a Serra d'Or i a Destino, respectivament) per demostrar la dimensió internacional - des de França i des d'Itàlia - de la cultura catalana. Cloïa el llibre l'edició de la conferència 
“Cataluña: cultura y sociedad”, que Porcel donà al Club Pueblo de Madrid, el 12 de febrer de 1970 i que, com la taula rodona, generà una considerable polèmica.

La intenció de Porcel a l'hora de reunir Aranguren, Laín i Ruiz-Giménez era explorar què pensava la intel-lectualitat castellana - la més receptiva, val a dir-ho - sobre el fet català. En general, els tres ponents acceptaven que la cultura catalana tenia una entitat pròpia - dins de la diversitat cultural espanyola, of course - i que la llengua catalana havia de gaudir d'un estatus oficial. Així i tot, no mostraven tanta unanimitat a l'hora d'aprovar una certa autonomia política: si Aranguren i, més matisadament Laín, no hi trobaven gaires inconvenients, Ruiz-Giménez, en canvi, preferia no pronunciar-s'hi. Era també Aranguren qui afirmava de manera manifesta el caràcter totalitari i "anticatalán" del règim franquista i la responsabilitat dels "catalanes vencedores", inclosos els intel-lectuals, com a "traidores a la catalanidad" (Porcel, Cataluña 28), atès que havien prioritzat els interessos personals als collectius. Més o menys oberts a una descentralització política i a un pluralisme cultural i nacional, no deixaven d'expressar els seus recels per la deriva política del catalanisme (i més encara sobre els Països Catalans) i, també, la seva inquietud per la incomprensió generalitzada del fet diferencial en el conjunt de la societat espanyola. Allò que, de tota manera, els desconcertà més fou la definició que Porcel (Cataluña 40) els etzibà del catalanisme com "la conciencia operante del hecho catalán", afirmació identitària prèvia a l'adscripció ideològica, o sigui al fet de considerar-se "comunista o conservador, anarquista o liberal".

Com a corollari, Cataluña vista desde fuera incloïa la conferència que l'escriptor mallorquí pronuncià al Club Pueblo de Madrid, en què es definia d'entrada com a catalanista, no pas per nostàlgia o rebel-lia, sinó "por razones de naturaleza y de geografía, de historia y de cultura" (Porcel, Cataluña 86). Amb voluntat pedagògica, Porcel hi feia notar l'anomalia sociolingüística de l'escriptor català, que ell havia viscut en primera persona, i hi traçava una visió sui generis de les fites més importants de la història política i cultural dels catalans. Al seu parer, la societat catalana no era "separatista" (en tot cas, només ho era si se l'obligava a ser "unionista") i, d'acord amb la seva ineludible vocació europea, havia de dialogar, internacionalitzar-se, expansionar-se, guanyar-se el reconeixement d'Espanya i del món. Per fer-ho, necessitava prèviament reconstruir-se i desplegar totes les potencialitats socioculturals, sense traves. A propòsit de l'escriptor català, sovint abocat a escriure en castellà, Porcel es queixava del fet que la seva situació fos tan precària professionalment, per la manca de presència del català en els mitjans de comunicació i en els diversos nivells de l'ensenyament. Tot amb tot, a pesar de les circumstàncies adverses, la cultura catalana havia experimentat una eclosió a la dècada dels seixanta que feia esperançar en el futur. Un futur que Porcel veia molt més condicionat per l'europeïtat que no pas per les conseqüències de la desfeta de 1939. 
Posteriorment, Porcel amplià la reflexió iniciada a Cataluña vista desde fuera amb un nou volum que duia el suggeridor títol de Debat català. Polèmica-diàleg amb la intel-lectualitat castellana (1973). Hi tornava a reproduir - en la versió de Serra d’Or - la taula rodona amb Aranguren, Laín i Ruiz-Giménez, la conferència que donà al Club Pueblo de Madrid, rebatejada com a "Succinta explicació de Catalunya per a castellans", i les entrevistes a Vilar i Sansone, però obria encara més el compàs enriquint els dos primers textos amb les opinions més o menys favorables o contràries que havien generat a la premsa coetània. Hi adjuntava, a més a més, una tria de les declaracions que havien fet diversos intel-lectuals castellans sobre Catalunya en les entrevistes aparegudes primer al setmanari Destino i després a Los encuentros. Per avivar encara la polèmica, hi adjuntava, com a colofó, l'article “Cultura catalana y comunicación peninsular”, publicat en castellà a la primera plana del diari $A B C$ el 22 de maig de 1973, i la reacció que havia causat en la premsa del moment.

En la introducció a Debat català, el periodista mallorquí es dolia de nou de l'anomalia politicocultural de l'escriptor català coetani, que havia d'actuar, per força, com a "desvetllador de consciències" o "lubrificador cívic" (Porcel, Debat 6) - unes expressions de clars ressons fusterians. Hi reconeixia l'encert d'haver optat per escriure "sobre el país" en els mitjans de difusió en castellà, "els únics d'importància permesos" (Porcel, Debat 7), ja que feien possible d'arribar a un públic molt més ampli. Amb l'aplom i l'arrogància que el caracteritzaven, s'hi mostrava satisfet per haver contribuït a divulgar, en sintonia amb les seves conviccions, el que era $i$ el que volia ser Catalunya. En contra del defecte que creia tan català d'actuar de manera subterrània o de recloure's endogàmicament, hi defensava "una posició ferma, inclús agressiva" i hi exposava la doble campanya que havia dut a terme com a periodista: d'un costat, oferir als lectors i polítics aliens la seva "versió catalana" i, de l'altre, sondejar l'opinió de la intel-lectualitat castellana sobre Catalunya (Porcel, Debat 8). Com havia propiciat a Los encuentros, sempre des de la posició del coneixement previ i objectiu de la realitat i des del diàleg obert.

Encara que no pogués parlar-ne amb tots els ets i uts, Porcel (Debat 9-10) al-ludia subreptíciament, en la introducció, a la polèmica que generà la taula rodona publicada a Serra d'Or i expedientada al TOP, una reacció que titllava de lògica, per tal com "des de la guerra no s'havia publicat una recapitulació semblant”. Malgrat l'enrenou que es produí, lamentava que el debat que havia promogut no tingués continuitat per tal de contribuir a crear un estat d'opinió com el que generaven les ressenyes, favorables o contràries, de l'edició de Cataluña vista desde fuera. Al seu entendre, Catalunya vivia massa tancada en si mateixa i calia 
que "s'autopublicités" i, en comptes de mirar-se al mirall, procurés treure lliçons útils del que passava al món.

Com hem apuntat, en contrast amb Cataluña vista desde fuera, Porcel inseria a Debat català una selecció de les opinions de la intel-lectualitat castellana sobre Catalunya, extractades de Destino, un recull d'articles publicats a la premsa sobre la seva conferència "Succinta explicació de Catalunya per a castellans" i l'article "Cultura catalana i comunicació peninsular", aparegut a l'ABC. Tot ben garbellat, sense que aportessin gaires novetats, les manifestacions de la intel-lectualitat castellana tendien, en el millor dels casos, a valorar la importància crucial de la qüestió per al futur polític de l'Estat espanyol (Areilza, Ridruejo, Serrano Suñer), a defensar la descentralització política i cultural (Delibes) o a elogiar de manera més o menys entusiasta la qualitat de la literatura catalana (Aleixandre). En canvi, la polèmica generada per la conferència es concentrà en la dura crítica que Porcel féu de la burgesia catalana, molt mal rebuda per una determinada premsa (Tele/ exprés, Solidaridad Nacional i Diario de Barcelona). En la introducció al llibre, hi aclarí aquest punt, que considerava que havia estat mal interpretat, i es mostrà contrari - com ja havia defensat a Exercicis més o menys espirituals - a "la famosa i falsa imatge de la Catalunya burgesa" (Porcel, Debat 16). No s'hi retractà, això no obstant, de l'opinió crítica sobre la burgesia catalana, sinó que encara s'hi reafirmà: "La veig dèbil, cada dia més, i arquetípica del pactisme més esburbat i erroni, havent perdut per complet les úniques coses que la van salvar en el passat: la creativitat industrial al segle xix, la consciència cultural en temps de Prat de la Riba" (Porcel, Debat 16). Sense embuts, titllava la reacció d'una part de la premsa barcelonina - Telelexprés i Diario de Barcelona - d'estar al servei de la burgesia, els interessos de la qual no eren catalans, sinó classistes. Com a cloenda del volum, Porcel reproduiia l'article "Cultura catalana i comunicació peninsular", en el qual advocava per la intercomunicació entre les cultures castellanes i catalanes, i per l'equilibri entre el català i el castellà als mitjans de comunicació i a l'ensenyament.

Vista en conjunt, la posició ideològica que destilllava l'obra de Baltasar Porcel durant els anys seixanta i primeríssims setanta no tenia, ni de lluny, una deriva "separatista". Ben bé al contrari, en el context d'una presa de consciència sobre la realitat (Nosaltres els valencians de Joan Fuster és de 1962) i d'un debat general sobre l'encaix de Catalunya a Espanya (recordem que Consideración de Cataluña, de Julián Marías, i Realidad de Cataluña, de Maurici Serrahima, s'havien publicat el 1966 i el 1967, respectivament), la seva dèria com a intel-lectual catalanista i d'esquerres que - amb criteri propi - volia incidir en l'opinió pública catalana i 
espanyola tenia, si més no, un doble objectiu: operar una sistemàtica desmitificació del catalanisme burgès des de posicions més o menys progressistes, un punt irreverents i contestatàries, i establir ponts de diàleg amb la intel-lectualitat castellana per donar a conèixer la realitat de Catalunya.

Amb una capacitat de treball enorme, impel-lida també per la urgència d'una professionalització literària, Porcel dugué a terme a través de la seva intervenció a la premsa coetània una diagnosi àmplia de la situació del país i una recuperació realista, antinostàlgica, de la seva memòria collectiva (sovint, en tots dos sentits, amb el testimoni i l'exemple que podien oferir personalitats emblemàtiques). Com havien fet Jaume Vicens Vives, Joan Fuster o Josep Melià, cadascú a la seva manera, Porcel assajava, des del seu propi projecte intel-lectual i cívic, un discurs polièdric sobre la realitat catalana que, d'una banda, entroncava amb la dinàmica progressiva de preguerra i, de l'altra, aprofundia en les potencialitats del present, amb la intenció que els catalans poguessin no solament autoconèixer-se de manera crítica, sense mediacions mitificadores, sinó també fer-se conèixer i comprendre terres enllà.

FRANCESC FOGUET I BOREU

Universitat Autònoma de Barcelona

\section{ANNEX \\ DOSSIER SOBRE BALTASAR PORCEL A L'OFICINA DE ENLACE}

1. Fitxa policial

PORCEL BALTASAR, escritor, novelista y autor teatral, con domicilio en la calle Calvet, $\mathrm{n}^{\circ}$. 51-53 de Barcelona.

En 10-5-1.965 citado en Nota como conferenciante en Mataró (Barcelona), en la dependencia de "El Racó" de la Sección Cultural y Recreativa de la Alianza Mataronense, sita en Melchor de Palau, 25.

Carece de otros antecedentes en los Archivos de esta Jefatura y se desconoce su ideología.

2. Primer informe (Madrid, 23 de maig de 1967)

Informes de Baltasar Porcel Pujol

Baltasar Porcel Pujol, autor del artículo titulado "Historia de una guerra", es natural de Andraitx (Baleares), nacido el 13 de Marzo de 1.937, hijo de Baltasar Porcel Covas y de Sebastiana Pujol Enseñat, de estado Soltero, profesión Escritor, utiliza el seudónimo de "Odín” y tuvo domicilio en Andraitx en la calle La Paz núm. 15. Actualmente reside en Barcelona, trabajando para la Editorial Planeta. 
Desde muy temprana edad, pasó a vivir a Palma de Mallorca, por trabajar su padre de "Mozo" en el Hotel Victoria.

En su pueblo natal, aunque solo suele ir de vez en cuando a visitar a su familia, sus paisanos le tienen en muy mal concepto, por haber escrito en libros y periódicos sátiras contra ellos. Según dicen, en Barcelona vive amancebado con la escritora Doña Concha Alós, esposa del Subdirector del periódico Baleares, Don Eliseo Feijóo. También que sus ideales políticos son de izquierdas y concretamente que comulga con ideas separatistas de los catalanes.

Sus padres antes del G. M. N. [Glorioso Movimiento Nacional] eran de ideología simpatizante con las derechas, igualmente que el resto de la familia. Actualmente explotan varias fincas de terreno de su propiedad, y viven al parecer apartados de la política, pendientes de su hijo que para ellos es un Dios.

Tiene un primo hermano, Don Pedro Porcel Moner, que es el más adicto al Régimen de todos sus parientes, siendo Delegado del Frente de Juventudes, de Andraitx y miembro de la Guardia de Franco. Otro primo hermano es Teniente Alcalde del Ayuntamiento de dicha población, y Lugarteniente de la Guardia de Franco. El resto de sus parientes, bastante numerosos, son todos de buena conducta y antecedentes, si bien varios tíos suyos, ya fallecidos que estuvieron en Cuba, se dice que eran masones y uno de ellos parece ser alcanzó el Grado 33 de la Asociación.

Se sabe que dicho Baltasar Porcel trabajó como amanuense o ayudante del famoso escritor Camilo José Cela. Parece ser que un gran amigo de Baltasar, con el que este se reúne al venir a Mallorca, es Don Bernardo Jofre Roca, abogado, oficial de telégrafos expulsado, que fué concejal de este Ayuntamiento en tiempos de la República y Canciller del Gobierno Rojo en Niza.

El epigrafiado colabora en el Diario de Barcelona, La Vanguardia Española, en la Revista Destino y en Serra d'Or, órgano de la Asociación de la Madre de Dios de Montserrat, y es autor de varias obras al estilo de Sartre y Camus, en lengua catalana, tituladas Els condemnats, Solnegre, Els escorpins y otras.

Se adjunta recorte del periódico Diario de Mallorca, de fecha 26 de Abril último, en el que aparece inserto el Artículo esquemático, objeto de este informe.

No es cierto haya sido presentado denuncia alguna, en la Auditoría de Guerra de esta Capitanía General.

Dicho artículo, según se dice, constituye parte de una obra publicada y representada en Barcelona.

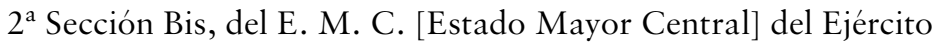
Madrid

$* * *$

\section{Història d'una guerra}

Primer home ben vestit: Ha estat un discurs veritablement meravellós!

President: Gràcies, ben estimats polítics. Condecoraré el meu secretari. Com segueix la marxa de la guerra? 
Primer home D'uniforme: Desgraciadament estacionària, senyor president. El general Magog és partidari d'atacar pel riu i el general Gog, en canvi, presentaria batalla per la muntanya.

SEgON HOME D'Uniforme: Els continus atacs de l'enemic ens han ocasionat sis o set mil baixes ...

President: Caram! Això és greu! I què eren?

Tercer home D'Uniforme: Soldats, Excel-lència. Els oficials ja saben com va la cosa i procuren anar alerta.

President: Menys mal, doncs. Per a suplir els soldats aquests, suposo que es podran cridar algunes lleves més, oi?

Primer home D'uniforme: Ja s'ha fet i hi ha abundància de gent fresca, Excel-lència.

President: I vosaltres, financers, què opineu de l'estat de coses?

FinANCER PRIMER: La indústria pesada porta una marxa ascendent. El mateix que la lleugera, ja que als fronts i amb els bombardeigs es destrossa molt. D'altra banda, ja se sap que la guerra i els preus cars són companys inseparables.

President: Me n'alegro, perquè havíem arribat a un marasme perillós.

\section{Baltasar Porcel}

El esquematismo y la violencia son, hasta hoy, los trazos más acusados de su obra dramática. Rebelde y subversivo, en definitiva creo que más hombre de acción que artista, ha conseguido incorporar de un modo muy personal las modernas técnicas expresivas (Sartre, Ionesco o Brecht), para manifestar, con innegable valentía, un pesimismo poco complejo y una ingenua crítica de nuestra sociedad de derechas. "Les seves peces teatrals - ha dicho con todo Molas — solen néixer d'una situació-límit que es desenrotlla sempre d'una manera desenfadada i fàcil, tibant, amb un llenguatge violent i eficaç. Així, totes elles esdevenen esquemàtiques i essencials, poètiques, i sobretot amenes. Cal esperar que sabrà ampliar aquests començaments tan brillants, i que, ben aviat, ocuparà un lloc dins les nostres lletres d'avui".

3. Segon informe (Madrid, 13 de febrer de 1970)

Asunto: BALTASAR PORCEL PUJOL

El epigrafiado nació el 14-3-1937 en Andraitx (Baleares), hijo de Baltasar y Sebastiana, soltero, escritor, con domicilio en Palma de Mallorca, calle de Marinero Moll D., núm. 16.

Al parecer, en la actualidad, reside en Barcelona, si bien no se ha podido determinar su domicilio exacto, estando trabajando en la Editorial "Planeta".

En algunos de sus escritos utiliza el seudónimo de "Odín".

En su pueblo natal está mal conceptuado, por haber escrito, en varios libros y revistas, sátiras contra los habitantes del pueblo. Según se comenta, en Barcelona, 
vive amancebado con Concha Alós, esposa del Subdirector del periódico Baleares de Palma de Mallorca. Se le considera como persona cuyas ideas políticas se inclinan hacia el separatismo catalán.

Tanto sus padres como sus numerosos parientes son simpatizantes al Régimen, llegando incluso, alguno de ellos, a ser Delegado del Frente de Juventudes, y miembro de la Guardia de Franco.

En sus comienzos, trabajó como ayudante del escritor Camilo José Cela.

Joven periodista, dramaturgo y narrador mallorquín, colabora asiduamente en La Vanguardia, Destino, Serra d'Or, este último órgano de la Asociación de la Madre de Dios de Montserrat. Es asimismo autor de varias obras, tanto en castellano como en catalán, habiendo obtenido en 1968 el premio Ramón Godó de La Vanguardia.

En 1967, escribe una serie de artículos en el periódico Diario de Mallorca, de Palma de Mallorca, bajo el título "Historia de una guerra", constituyendo este artículo parte de una obra publicada y representada en Barcelona.

En mayo de 1969, Don Carlos Robles Piquer se dirigió por escrito al director general de Seguridad, interesando le fuera concedido pasaporte especial para Rusia al propietario de Editorial Planeta, Don José Manuel Lara, al cual deseaba acompañar en este viaje el informado, siéndole denegado el pasaporte.

En este mismo año aparece como uno de los firmantes de un escrito dirigido al Ministro de Gobernación, denunciando supuestos malos tratos a presos y detenidos políticos.

Se le conoce como uno de los asiduos conferenciantes en el Club de Amigos de la Unesco.

Madrid, 13 de Febrero de 1970

4. Fragments subratllats de l'entrevista publicada al Diario de Barcelona (30 de gener de 1972)

Casi toda la versión real de las cosas no correspondía a la pública, a la oficial. Se me planteó el problema de indagar en la vida real del país.

He entrevistado a Dionisio Ridruejo, cuya imagen popular y oficial era el de un fascista retirado. A mí Ridruejo me pareció una persona moralmente muy digna. Me pareció un intelectual y un ex aprendiz de político muy digno.

No creo haber entrevistado nunca a un político medianamente potable. ¡Y eso que he entrevistado a muchos! En general, los políticos me parecen una gente bastante inmoral o al menos amoral.

¿Que si me considero un autor bilingüe? Me considero un escritor bilingüe catalán. Toda mi obra de creación la he hecho primero en catalán y mi obra periodística la he hecho generalmente en castellano. [...]. Me he encontrado ante el problema 
de pertenecer a una cultura minoritaria con muchos problemas metidos dentro de sí y en el marco de una de las culturas mayoritarias del mundo, que es la de la lengua castellana. [...] He usado el castellano como mi segunda lengua puente. [...] No considero que sea ninguna traición el escribir en castellano [...]. Mi obra de creación, la obra en la cual juego mis bazas importantes, al menos para mí, es la que hago en catalán y me siento vinculado a esta cultura de una forma absoluta.

\section{REFERÈNCIES}

Fuster, Joan. Nosaltres els Valencians. Barcelona: Edicions 62, 1962.

Juliá, Santos. Nosotros, los abajo firmantes. Una historia de España a través de manifiestos y protestas (1896-2013). Barcelona: Galaxia-Gutenberg, 2014.

Marías, Julián, Consideración de Cataluña. Barcelona: Aymà, 1966.

Planas, Antoni. Baltasar Porcel. La novel-la de la vida. Palma: Lleonard Muntaner, 2003.

Porcel, Baltasar. Arran de mar. Viatges i fantasies. Barcelona: Selecta, 1967.

—. "Catalunya vista des de Castella”. Serra d'Or febrer 1970.

-. Cataluña vista desde fuera. Barcelona: Llibres de Sinera, 1970.

—. "Cultura catalana y comunicación peninsular”. ABC 22 maig 1973.

- Debat català. Polèmica-diàleg amb la intel-lectualitat castellana. Barcelona: Selecta, 1973.

-. Desintegraciones capitalistas. Barcelona: Planeta, 1972.

-. El conflicto árabe'israelí. Barcelona: Ariel, 1969.

-. Els xuetes mallorquins. Quinze segles de racisme. Barcelona: Edicions 62, 1969.

-. Exercicis més o menys espirituals. Barcelona: Edicions 62, 1969.

-. Grans catalans d'ara. Barcelona: Destino, 1972.

—. "Historia de una guerra". Diario de Mallorca 26 abril 1967.

—. La revuelta permanente. Barcelona: Planeta, 1978.

- Las sombras chinescas. Barcelona: Taber, 1968.

- Los catalanes de hoy. Barcelona: Seix Barral, 1971.

-. Los encuentros. Primera serie. Barcelona: Destino, 1969.

-. Los encuentros. Segunda serie. Barcelona: Destino, 1971.

—. Obres completes. 7 vols. Barcelona: Proa, 1991-1997.

—. Teatre. Palma de Mallorca: Daedalus, 1965.

-. Ulisses a alta mar. Barcelona: Edicions 62, 1997.

—. Viaje a las Baleares menores. Barcelona: Taber, 1968.

Serrahima, Maurici. Realidad de Cataluña. Editorial Aymà, 1967.

Trueta, Josep. The Spirit of Catalonia. Oxford, UK: G. Cumberledge, Oxford University Press, 1946. 